\title{
Pengaruh Pembubutan Dengan Sistem Minimum Quantity Lubrication (MQL) Dan Dry Cutting Terhadap Kekasaran Permukaan Dan Konsumsi Daya Listrik Pada Baja Karbon Sedang
}

\author{
Rusdi Nur ${ }^{1 *}$, Edhy Gazali ${ }^{2}$, dan Faris Farid R. ${ }^{3}$ \\ 1,2,3 Jurusan Teknik Mesin, Politeknik Negeri Ujung Pandang, Makassar 90245, Indonesia \\ *rusdinur@poliupg.ac.id
}

\begin{abstract}
Background of research on the effect of turning with the method of minimum quantity lubrication (MQL) and dry cutting on surface roughness and electrical power consumption in medium carbon steel. The purpose of this study was to determine the effect of turning with minimum quantity lubrication (MQL) and dry cutting and to determine the electrical power consumption of the lathe to improve surface roughness. In the industrial world repairing surface roughness of work pieces is preferably using turning process so it is necessary to find a cooling medium that can reduce high temperatures, so as to improve surface roughness, reduce tools and find methods of improving surface hardness that are good and efficient in the use of electric power in the process turning of medium carbon steel. Stages in analyzing surface roughness in the turning process using the method of minimum quantity lubrication (MQL) and dry cutting. The right method is obtained to reduce the level of roughness in the turning process, using the minimum quantity lubrication (MQL) method.
\end{abstract}

Keywords: Lathe, surface roughness, power consumption

\begin{abstract}
Abstrak: Latar belakang penelitian tentang pengaruh pembubutan dengan metode minimum quantity lubrication (MQL) dan dry cutting terhadap kekasaran permukaan dan konsumsi daya listrik pada baja karbon sedang. Tujuan penelitian ini adalah untuk mengetahui pengaruh pembubutan dengan minimum quantity lubrication (MQL) dan dry cutting serta mengetahui konsumsi daya listrik dari mesin bubut untuk memperbaiki kekasaran permukaan. Pada dunia industri memperbaiki kekasaran permukaan benda kerja lebih disukai menggunakan proses pembubutan sehingga perlu untuk menemukan media pendingin yang dapat mengurangi suhu tinggi, sehingga dapat memperbaiki kekasaran permukaan, mengurangi alat bantu dan menemukan metode perbaikan kekerasan permukaan yang baik dan efisien dalam penggunaan daya listrik pada proses pembubutan baja karbon sedang. Tahapan dalam menganalisis kekasaran permukaan pada proses pembubutan dengan menggunakan metode minimum quantity lubrication (MQL) dan dry cutting. Ditemukan metode yang tepat untuk mengurangi tingkat kekasaran dalam proses pembubutan yaitu menggunakan metode minimum quantity lubrication (MQL).
\end{abstract}

Kata kunci : Bubut, kekasaran permukaan, konsumsi daya listrik

\section{PENDAHULUAN}

Dalam proses manufaktur, mesin bubut konvensional telah dikenal fungsi dan perannya untuk membuat suatu komponen. Untuk mendapatkan kualitas pemotongan dan pemakanan yang baik diperlukan komponen yang berkualitas serta mesin yang dapat beroperasi dengan optimal, suatu mesin dalam keadaan prima dan elemen-elemen mesin tersebut dapat berfungsi dengan baik tanpa adanya masalah terhadap komponen-komponennya [1-2]. Pemilihan komponen dimaksud adalah pengaruh dari pemakanan benda kerja, pahat bubut menjadi salah satu komponen dalam proses pemesinan selain mesin bubut dan benda kerja. 
Dalam dunia industri, tingkat kekasaran suatu produk sangat mempengaruhi fungsi dari produk tersebut, dalam proses pemotongan logam terutama proses bubut, produktifitas dan kualitas permukaan produk dapat ditingkatkan dengan menaikkan putaran spindle atau kecepatan pomotongan serta mengatur laju pemakanan [3]. Hal ini akan menyebabkan tingginya temperatur pada daerah pemotongan yang akan mempengaruhi keausan pahat dan kekasaran permukaan yang dapat menyebabkan cacat produk. Untuk itu dibutuhkan media pendingin yang dapat mengurangi tingginya temperatur sehingga dapat memperbaiki kekasaran permukaan dan mengurangi keausan pahat [4].

Proses bubut merupakan proses pembentukan material dengan membuang sebagian material dalam bentuk geram akibat adanya gerak relatif pahat terhadap benda kerja, dimana benda kerja diputar pada spindle dan pahat dihantarkan ke benda kerja secara translasi [5]. Pada proses pembubutan kekasaran dari hasil pekerjaan merupakan hal yang sangat penting. Kekasaran permukaan dipengaruhi beberapa faktor seperti kecepatan makan (feeding), kedalaman potong, media pendingin, gerak makan dan jenis material lainnya [6-9].

Proses pembubutan pada umumnya menggunakan pendinginan basah dengan persentasi perbandingan air dan oli 1:1 sampai 1:40. Dalam penelitian ini akan dilakukan proses teknik pembubutan Minimum quantity Lubrication (MQL) dan Dry Cutting. Teknik ini memanfaatkan efek gaya gravitasi sehingga lubricant akan bekerja ke kontak antara pahat dan benda kerja [10-13]. Selain metode MQL akan dilakukan juga metode dry cutting, yaitu metode tanpa menggunakan sistem pendingin [12].

Minimum quantity lubrication (MQL) merupakan salah satu teknik lubrikasi dimana lubricant dan udara bertekanan ditembakkan ke kontak antara pahat dan benda kerja. Teknik MQL ini akan mengurangi gesekan antar pahat dan benda kerja sehingga akan mengurangi laju kenaikan temperatur pahat dan akhirnya dapat menaikkan umur pahat. Hadirnya MQL sebagai parameter pelumasan untuk mengetahui tingkat kekasaran permukaan pada proses pembubutan. Mengingat begitu pentingnya arti kekasaran suatu komponen terutama poros, maka harus dapat dibuat produk yang mempunyai tingkat kekasaran yang sesuai kriteria. Untuk mengetahui jenis kekasaran pada suatu benda kerja atau hasil produksi dengan proses permesinan dapat digunakan suatu alat ukur kekasaran permukaan (roughness tester).

Hasilnya, kemudian digunakan untuk membandingkan proses pembubutan antara MQL dan dry cutting pada kekasaran permukaan. Untuk mengetahui tekstur kekasaran permukaan (Ra) yang menghasilkan harga dan tingkat kekasaran $(\mathrm{N})$. Selain itu, perlu dilakukan perhitungan agar nilai kekasaran permukaan sebanding dengan pemakaian listrik [14] dengan menggunakan alat clampmeter. Hasil pemakaian listrik pada proses pembubutan akan dikonversikan ke dalam nilai Rupiah (Rp).

Maka dengan itu penulis mencoba melakukan penelitian dengan judul "pengaruh pembubutan dengan sistem minimum quantity lubrication (MQL) dan dry cutting terhadap kekasaran permukaan dan konsumsi daya listrik pada baja karbon sedang". Dengan menggunakan metode tersebut diharapkan dapat membantu dalam menentukan kekasaran permukaan yang baik serta efisien dalam penggunaan daya listrik pada proses pembubutan baja karbon sedang.

\section{METODE PENELITIAN}

Penelitian akan dilakukan di bengkel Mekanik Jurusan Teknik Mesin, Politeknik Negeri Ujung Pandang karena sebagian besar mesin dan peralatan serta alat ukurtersedia dengan lengkap yang menunjang penelitian yang akan dilakukan. Waktu pelaksanaan kurang lebih dikerjakan selama 1 bulan (Juli 2018).

Dalam pengambilan data kami menggunakan Proses pembubutan spesimen dengan menggunakan tanpa pendingin (dry cutting) dan MQL (Minimum Quantity Lubrication), Proses 
43 Rusdi Nur, Edhy Gazali, Faris Farid R. Pengaruh Pembubutan Dengan Sistem Minimum Quantity Lubrication (MQL) Dan Dry Cutting Terhadap Kekasaran Permukaan Dan Konsumsi Daya Listrik Pada Baja Karbon Sedang

pengukuran konsumsi daya listrik yang dilakukan dengan menggunakan clampmeter, dimana posisi clampmeter ditempelkan pada kabel yang berada dimesin bubut serta mengatur terlebih dahulu skala arus pada clampmeter yang ditetukan yaitu 20A, Pengujian tingkat kekasaran dari material yang telah dibubut dengan menggunakan alat ukur surface roughness tester SURFTEST SJ-310 yang ditempelkan pada permukaan benda kerja dan perlu dilakukan pengulangan data pengambilan sampel untuk setiap parameter yang digunakan.

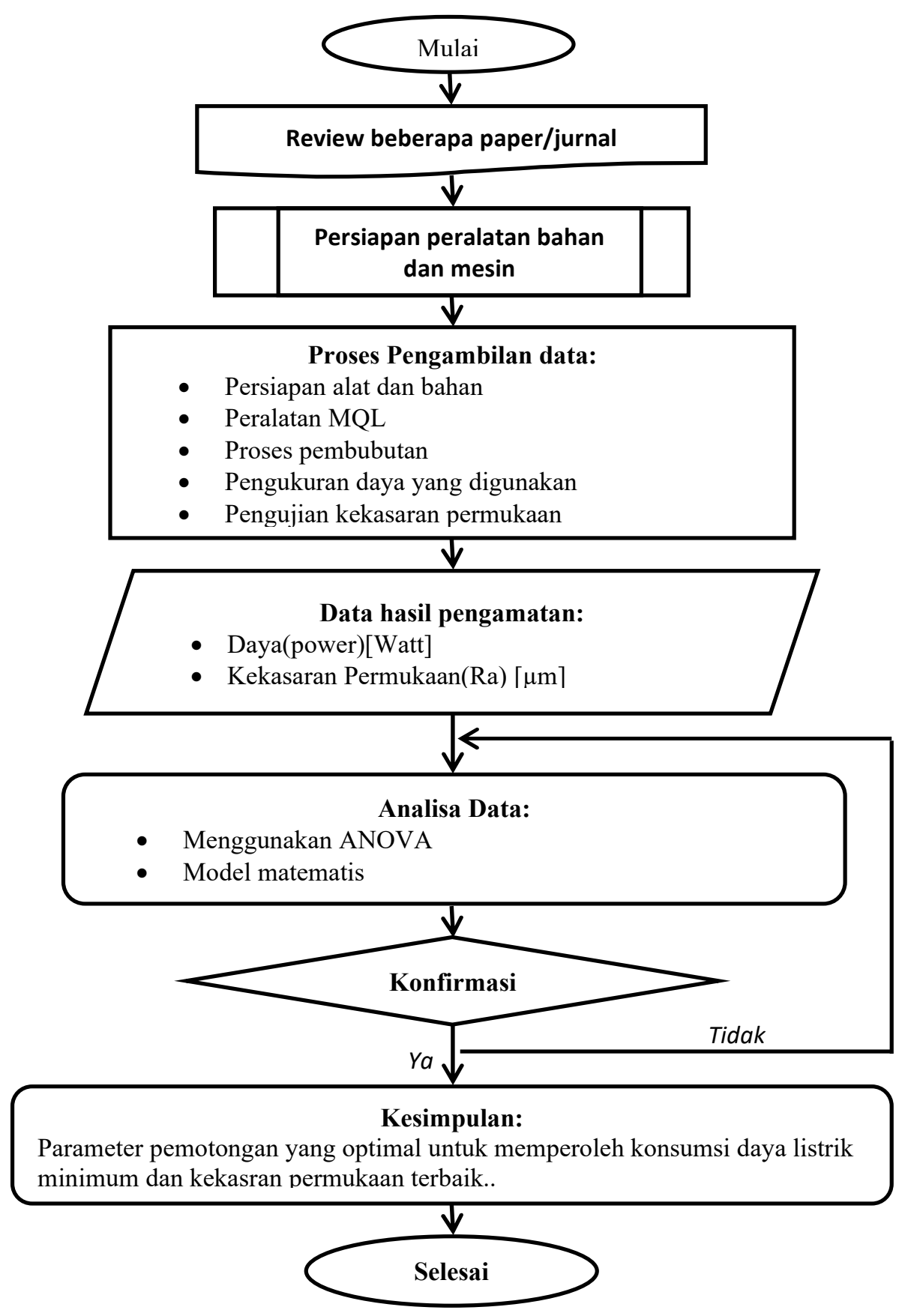

Gambar 1. Diagram alir penelitian 


\section{HASIL DAN PEMBAHASAN}

Berdasarkan hasil penelitian dan analisa data yang telah dilakukan, maka dapat disimpulkan Konsumsi daya listrik pada proses pembubutan hanya dipengaruhi oleh variabel putaran, dimana semakin besar putaran yang digunakan maka nilai konsumsi daya listrik semakin tinggi, sebaliknya semakin kecil putaran yang digunakan maka nilai konsumsi daya listrik semakin rendah. Sedangkan laju pemakanan dapat berpengaruh terhadap konsumsi daya listrik dan Media pendingin memberi pengaruh yang signifikan terhadap kekasaran permukaan benda kerja dimana jika menggunakan pendingin (MQL) semakin besar nilai kehalusan benda kerja.

Konsumsi daya listrik adalah perhitungan nilai arus listrik dikalikan dengan nilai tegangan listrik mesin bubut yang tersedia yaitu $220 \mathrm{~V}$. Daya yang digunakan oleh mesin bubut menggunakan tiga fasa motor dimana efesiensi mesin $85 \%$. P(daya) dihitung menggunakan persamaan sebagai berikut:

Dengan:

$$
\begin{aligned}
& P=P_{o}+P_{t} \\
& P_{o}=P_{t}=V \times I \times \sqrt{3} \times 85 \%
\end{aligned}
$$

$$
\begin{aligned}
\mathrm{V} & =\text { tegangan }(\mathrm{v}) \\
\mathrm{I} & =\operatorname{arus}[\mathrm{A}] .
\end{aligned}
$$

Dari pengukuran yang dilakukan didapatkan nilai arus tanpa pemebenan yaitu $\mathrm{I} 0=0.05 \mathrm{~A}$ dan nilai rata-rata arus saat proses pebubutan yaitu $\mathrm{It}=6.75 \mathrm{~A}$. sehingga nilai daya dapat diperoleh dengan menggunakan persamaan diatas yaitu:

$$
\begin{aligned}
& P=P_{o}+P_{t} \\
& P=\left(V x I_{o} \times \sqrt{3} \times 85 \%\right)+\left(V \times I_{t} \times \sqrt{3} \times 85 \%\right) \\
& P=(220 \times 0,05 \times \sqrt{3} \times 85 \%)+(220 \times 6,75 \times \sqrt{3} \times 85 \%) \\
& P=16,19+2189,52 \\
& P=2205,71 \text { watt }
\end{aligned}
$$
kerja:

Berikut grafik konsumsi daya listrik pada proses pembubutan dari setiap spesimen benda

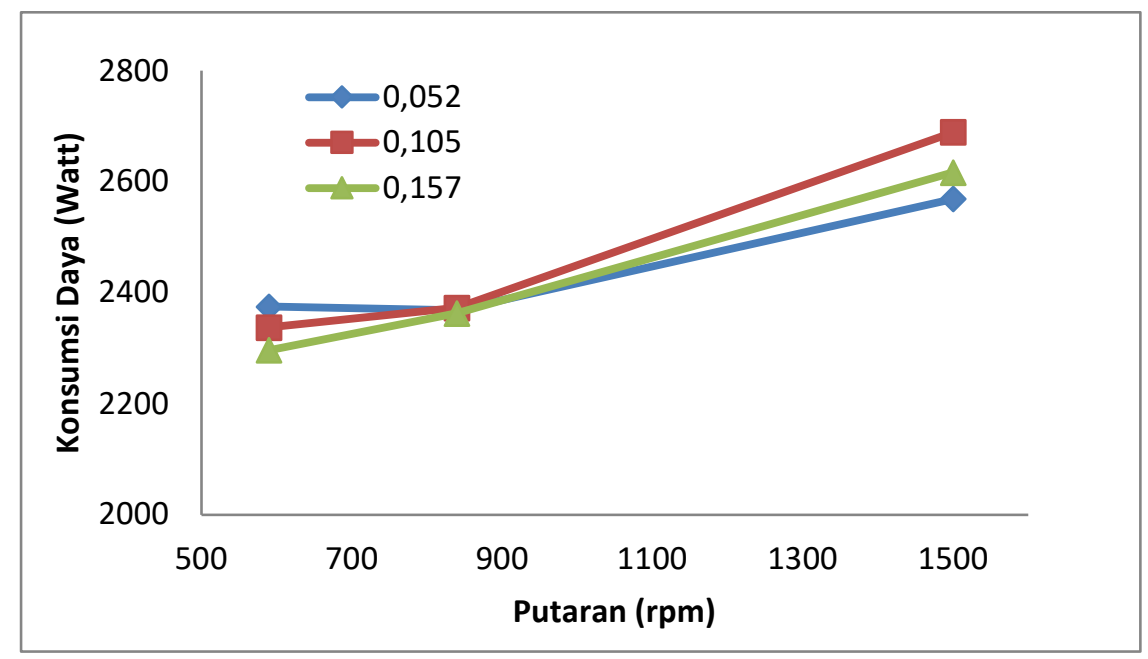

Gambar 2. Grafik Konsumsi Daya Listrik Baja ST42 Dry Cutting.

Pada pembubutan Baja ST42 dengan metode dry cutting diperoleh bahwa berdasarkan hasil perhitungan daya dengan variasi putaran dan laju pemakanan pada gambar 2, menunjukkan bahwa konsumsi daya tertinggi terdapat pada putaran $1500 \mathrm{rpm}$ dan laju pemakanan $0.105 \mathrm{rev} / \mathrm{mm}$ sebesar 
45 Rusdi Nur, Edhy Gazali, Faris Farid R. Pengaruh Pembubutan Dengan Sistem Minimum Quantity Lubrication (MQL) Dan Dry Cutting Terhadap Kekasaran Permukaan Dan Konsumsi Daya Listrik Pada Baja Karbon Sedang

2689 Watt. dan sebaliknya konsumsi daya terendah terdapat pada putaran $590 \mathrm{rpm}$ dan laju pemakanan $0.157 \mathrm{rev} / \mathrm{mm}$ yaitu sebesar $2296 \mathrm{Watt}$.

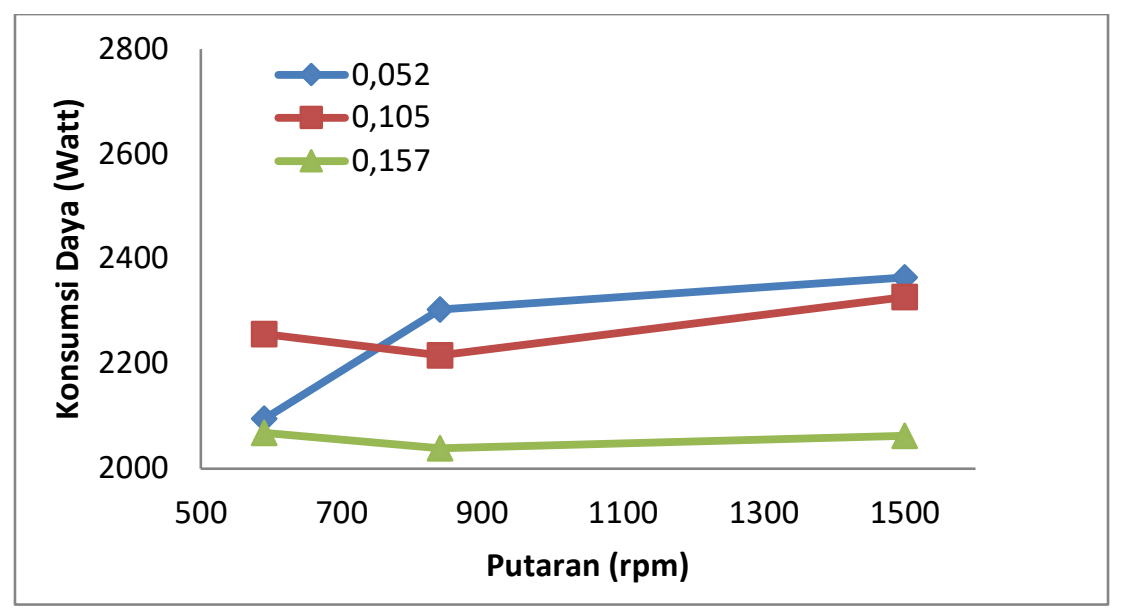

Gambar 3. Grafik Konsumsi Daya Listrik Baja ST60 Dry Cutting.

Pada pembubutan Baja ST60 dengan metode dry cutting diperoleh bahwa berdasarkan hasil perhitungan daya dengan variasi putaran dan laju pemakanan pada gambar 3, menunjukkan bahwa konsumsi daya tertinggi terdapat pada putaran $1500 \mathrm{rpm}$ dan laju pemakanan $0.052 \mathrm{rev} / \mathrm{mm}$ sebesar 2364 Watt. Dan sebaliknya konsumsi daya terendah terdapat pada putaran $840 \mathrm{rpm}$ dan laju pemakanan $0.157 \mathrm{rev} / \mathrm{mm}$ yaitu sebesar 2038 Watt.

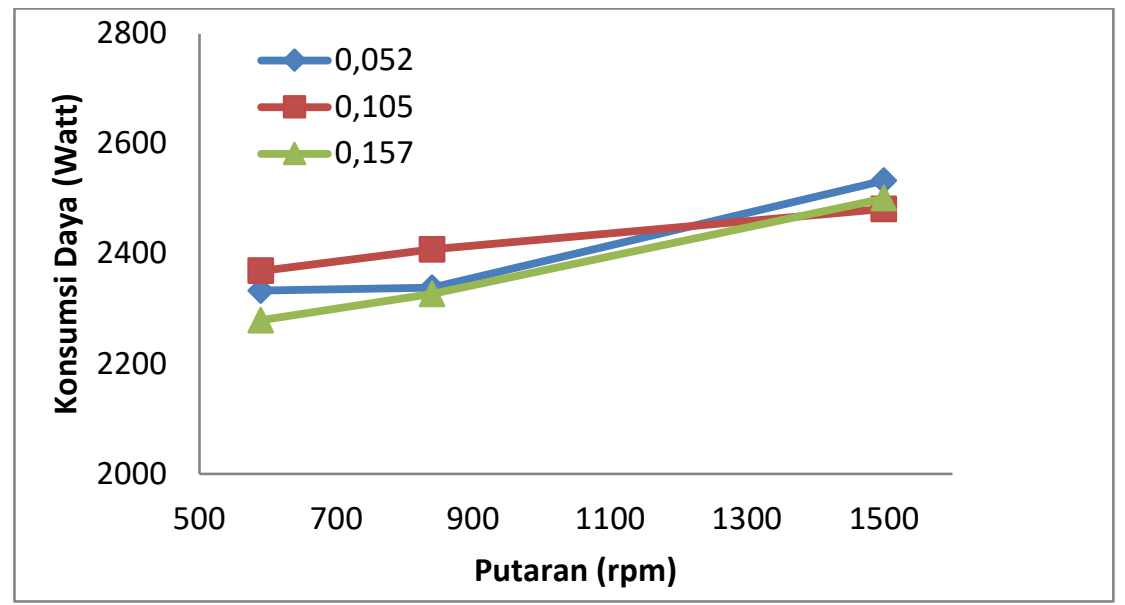

Gambar 4. Grafik Konsumsi Daya Listrik Baja ST42 MQL.

Pada pembubutan Baja ST42 dengan metode minimum quantity lubrication (MQL) diperoleh bahwa berdasarkan hasil perhitungan daya dengan variasi putaran dan laju pemakanan pada gambar 4, menunjukkan bahwa konsumsi daya tertinggi terdapat pada putaran $1500 \mathrm{rpm}$ dan laju pemakanan $0.052 \mathrm{rev} / \mathrm{mm}$ sebesar 2533 Watt. dan sebaliknya konsumsi daya terendah terdapat pada putaran 590 $\mathrm{rpm}$ dan laju pemakanan $0.157 \mathrm{rev} / \mathrm{mm}$ yaitu sebesar 2279 Watt.

Pada pembubutan Baja ST60 dengan metode minimum quantity lubrication (MQL) diperoleh bahwa berdasarkan hasil perhitungan daya dengan variasi putaran dan laju pemakanan pada gambar 
5, menunjukkan bahwa konsumsi daya tertinggi terdapat pada putaran $1500 \mathrm{rpm}$ dan laju pemakanan $0.105 \mathrm{rev} / \mathrm{mm}$ sebesar 2578 Watt. dan sebaliknya konsumsi daya terendah terdapat pada putaran 840 $\mathrm{rpm}$ dan laju pemakanan $0.157 \mathrm{rev} / \mathrm{mm}$ yaitu sebesar $2293 \mathrm{Watt}$.

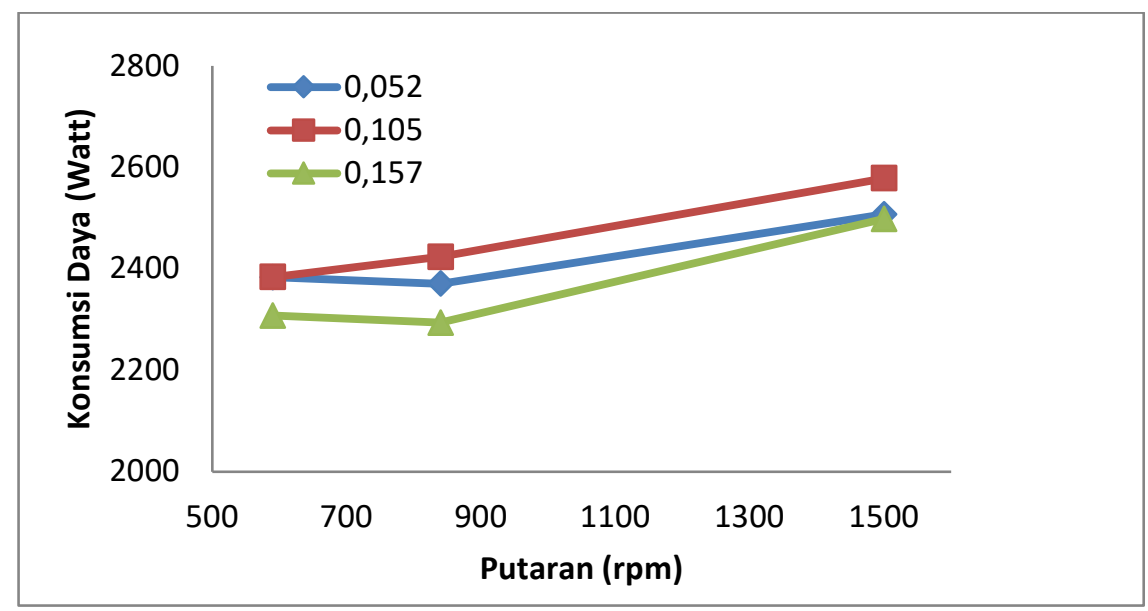

Gambar 5. Grafik Konsumsi Daya ListrikBaja ST60 MQL.

Berdasarkan grafik pada gambar 2 sampai dengan gambar 5, diperoleh bahwa daya dari setiap spesimen benda kerja berbeda-bedadimana daya berbanding lurus dengan putaran mesin bubut saat proses pembubutan.

Dari hasil analisa data tersebut diatas memperlihatkan bahwa konsumsi daya listrik dari setiap spesimen benda kerja pembubutan dengan putaran $590 \mathrm{rpm}, 840 \mathrm{rpm}, 1500 \mathrm{rpm}$ dan laju pemakanan pemakanan $0.052 \mathrm{rev} / \mathrm{mm}, 0.105 \mathrm{rev} / \mathrm{mm}, 0.157 \mathrm{rev} / \mathrm{mm}$. Konsumsi daya listrik tertinggi pada perlakuan dry cutting terdapat pada baja ST42 dengan putaran $1500 \mathrm{rpm}$ dan laju pemakanan 0.105 $\mathrm{rev} / \mathrm{mm}$ sedangkan terkecil terdapat pada baja ST60 dengan putaran $840 \mathrm{rpm}$ dan laju pemakanan $0.157 \mathrm{rev} / \mathrm{mm}$. Untuk perlakuan menggunakan metode minimum quantity lubrication (MQL) konsumsi daya listrik tertinggi terdapat pada baja ST60 dengan putaran $1500 \mathrm{rpm}$ dan laju pemakanan $0.105 \mathrm{rev} / \mathrm{mm}$ sedangkan terkecil terdapat pada baja ST42 dengan putaran $590 \mathrm{rpm}$ dan laju pemakanan $0.157 \mathrm{rev} / \mathrm{mm}$.

Dari semua spesimen benda kerja dengan variasi putaran dan laju pemakanan dapat diperoleh bahwa yang memberikan kualitas nilai konsumsi daya listrik terkecil terdapat pada baja ST60 dry cutting dengan putaran $840 \mathrm{rpm}$ dan laju pemakanan $0.157 \mathrm{rev} / \mathrm{mm}$.

Pengujian kekasaran permukaan dilakukan dengan menggunakan alat ukur kekasaran permukaan (surface roughness tester) SURFTEST SJ-310. Pada pembubutan menggunakan pendingin sebelum melakukan pengujian kekasaran permukaan pada benda kerja, terlebih dahulu benda kerja dibersihkan dari air pendingindan partikel-pertikel yang mengendap pada permukaan benda kerja karena dapat menyebabkan hasil pengujian yang tidak akurat. Oleh karena itu, benda kerja dibersihkan dengan menggunakan kuas dan majun yang dapat membersihkan permukaan benda kerja, namun untuk pembubutan tanpa pendingin langsung dapat melakukan pengujian.

Setiap kombinasi antara putaran dan laju pemakanan dilakukan pengulangan pembubutan sebanyak 3 kali dan pengujian kekasaran permukaan dilakukan sebanyak 3 kali dalam setiap pembubutan. sehingga pengujian kekasaran permukaan yang didapatkan dari setiap spesimen pembubutan sebanyak 99 data hasil kekasaran permukaan. Setelah melakukan pengambilan data kekasaran permukaan. data penelitian selanjutnya dihitung nilai rata-rata kekasaran permukaannya untuk setiap kombinasi putaran dan laju pemakanan setiap spesimen pembubutan benda kerja. 
47 Rusdi Nur, Edhy Gazali, Faris Farid R. Pengaruh Pembubutan Dengan Sistem Minimum Quantity Lubrication (MQL) Dan Dry Cutting Terhadap Kekasaran Permukaan Dan Konsumsi Daya Listrik Pada Baja Karbon Sedang

Adapun hasil dari pengujian kekasaran permukaan dari setiap sepesimen benda kerja pembubutan ditunjukkan pada tabel berikut:

Dari hasil perhitungan yang dilakukan, dibuat dalam bentuk grafik agar lebih memudahkan menganalisis hasil perhitungan kekasaran permukaan poros pada proses pembubutan, maka diperoleh grafik seperti yang terlihat pada gambar 6 sampai dengan gambar 9 . benda kerja:

Berikut grafik kekasaran permukaan poros pada proses pembubutan dari setiap spesimen

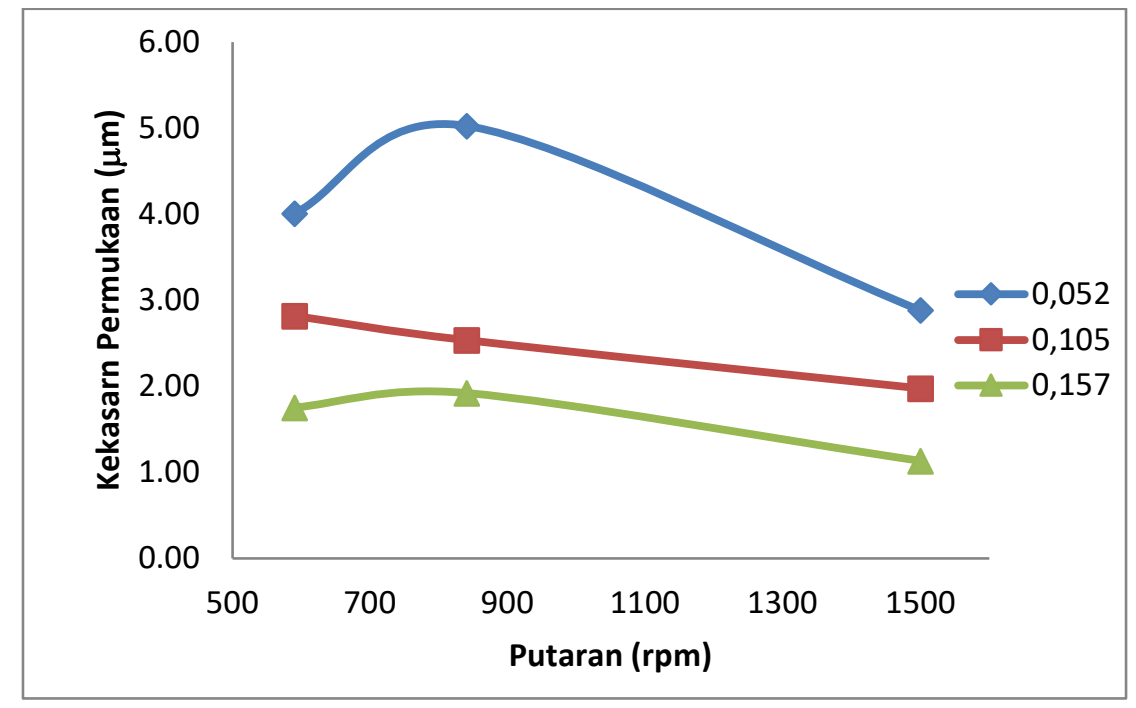

Gambar 6. Grafik Kekasaran Permukaan Baja ST42 Dry Cutting

Pada pembubutan Baja ST42 dengan metode dry cutting diperoleh bahwa berdasarkan hasil pengukurankekasaran permukaandengan variasi putaran dan laju pemakanan pada gambar 6, menunjukkan bahwa kekasaran permukaan tertinggi terdapat pada putaran $840 \mathrm{rpm}$ dan laju pemakanan $0.052 \mathrm{rev} / \mathrm{mm}$ sebesar $5.026 \mu \mathrm{m}$. dan sebaliknya kekasaran permukaan terendah terdapat pada putaran $1500 \mathrm{rpm}$ dan laju pemakanan $0.157 \mathrm{rev} / \mathrm{mm}$ yaitu sebesar $1.132 \mu \mathrm{m}$. 


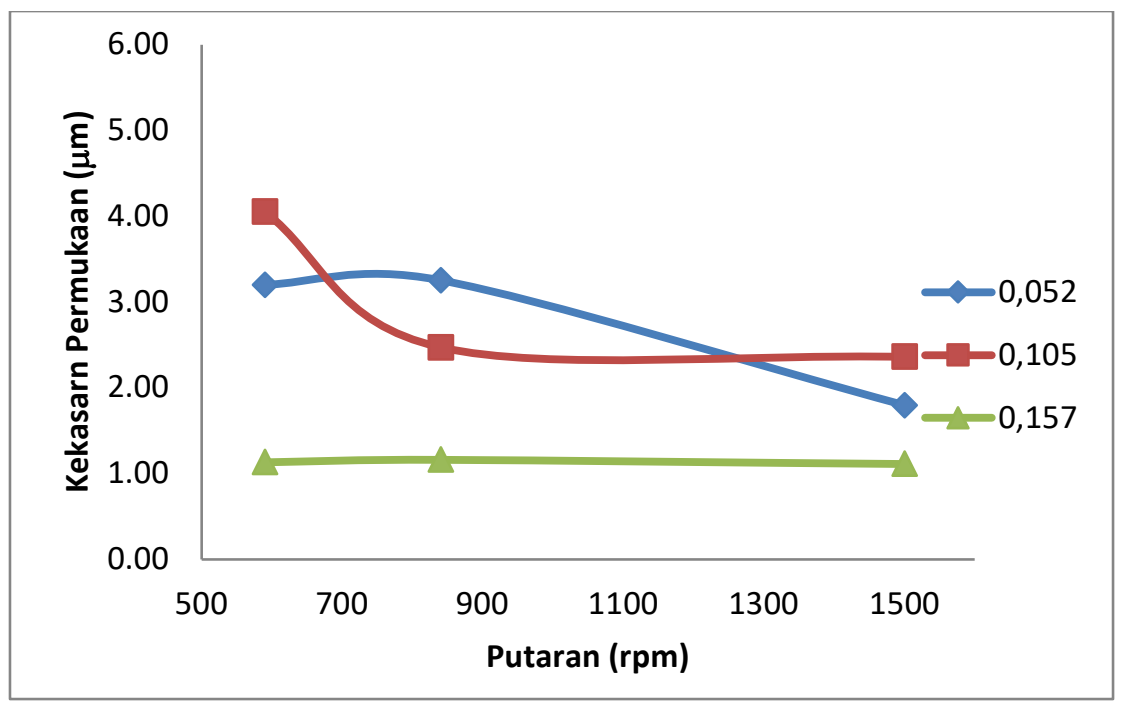

Gambar 7. Grafik Kekasaran Permukaan Baja ST60 Dry Cutting

Pada pembubutan Baja ST60 dengan metode dry cutting diperoleh bahwa berdasarkan hasil pengukuran kekasaran permukaan dengan variasi putaran dan laju pemakanan pada gambar 7, menunjukkan bahwa kekasaran permukaan tertinggi terdapat pada putaran $590 \mathrm{rpm}$ dan laju pemakanan $0.105 \mathrm{rev} / \mathrm{mm}$ sebesar $4.056 \mu \mathrm{m}$. dan sebaliknya kekasaran permukaan terendah terdapat pada putaran $1500 \mathrm{rpm}$ dan laju pemakanan $0.157 \mathrm{rev} / \mathrm{mm}$ yaitu sebesar $1.113 \mu \mathrm{m}$.

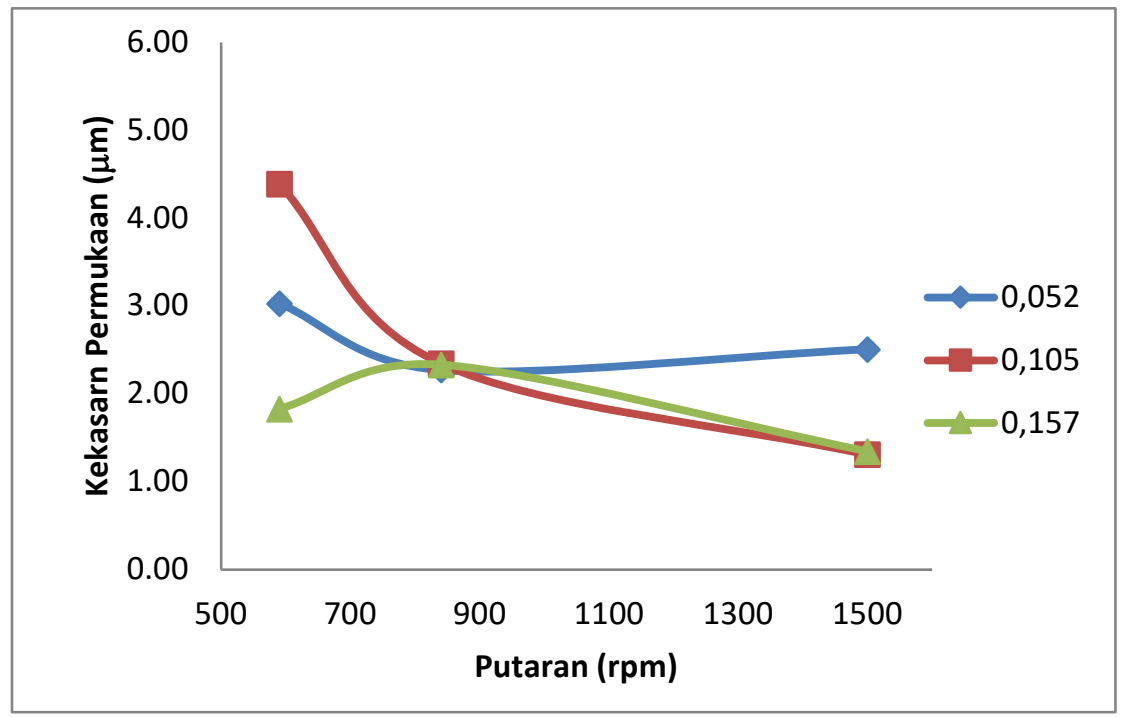

Gambar 8. Grafik Kekasaran PermukaanBaja ST42 MQL

Pada pembubutan Baja ST42 dengan metode minimum quantity lubrication (MQL) diperoleh bahwa berdasarkan hasil pengukuran kekasaran permukaan dengan variasi putaran dan laju pemakanan pada gambar 8, menunjukkan bahwa kekasaran permukaan tertinggi terdapat pada putaran $590 \mathrm{rpm}$ dan laju pemakanan $0.105 \mathrm{rev} / \mathrm{mm}$ sebesar $4.392 \mu \mathrm{m}$. dan sebaliknya kekasaran permukaan terendah terdapat pada putaran $1500 \mathrm{rpm}$ dan laju pemakanan $0.105 \mathrm{rev} / \mathrm{mm}$ yaitu sebesar $1.309 \mu \mathrm{m}$ 
49 Rusdi Nur, Edhy Gazali, Faris Farid R. Pengaruh Pembubutan Dengan Sistem Minimum Quantity Lubrication (MQL) Dan Dry Cutting Terhadap Kekasaran Permukaan Dan Konsumsi Daya Listrik Pada Baja Karbon Sedang

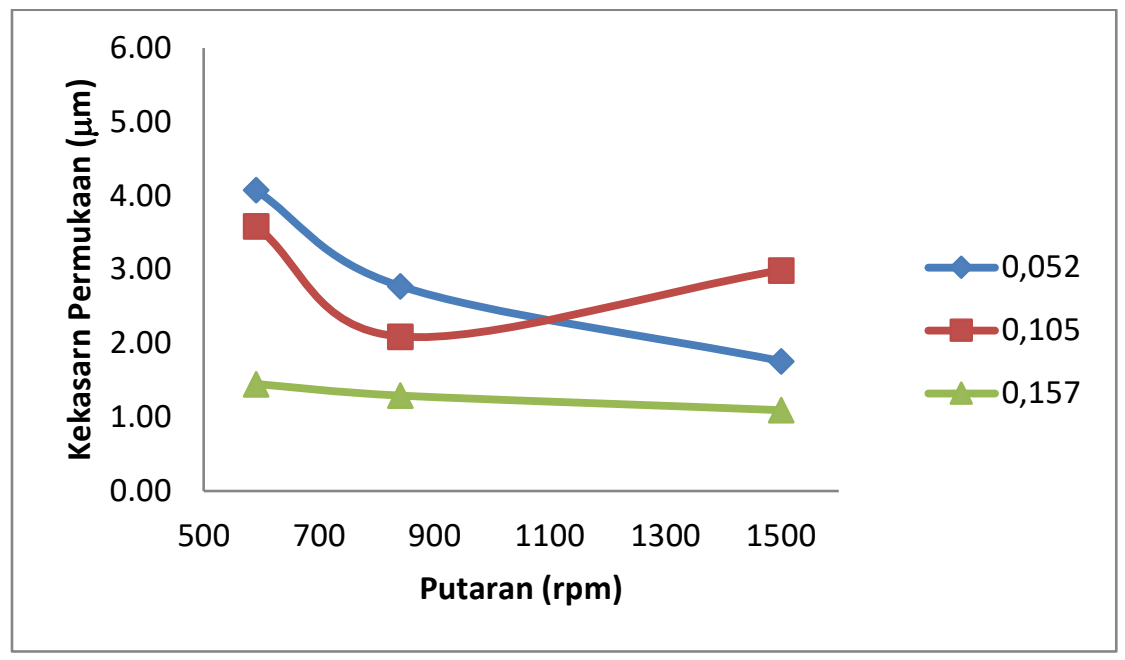

Gambar 9. Grafik Kekasaran PermukaanBaja ST60 MQL

Pada pembubutan Baja ST60 dengan metode minimum quantity lubrication (MQL) diperoleh bahwa berdasarkan hasil pengukuran kekasaran permukaan dengan variasi putaran dan laju pemakanan pada gambar 9, menunjukkan bahwa kekasaran permukaan tertinggi terdapat pada putaran $590 \mathrm{rpm}$ dan laju pemakanan $0.052 \mathrm{rev} / \mathrm{mm}$ sebesar $4.079 \mu \mathrm{m}$. dan sebaliknya kekasaran permukaan terendah terdapat pada putaran $1500 \mathrm{rpm}$ dan laju pemakanan $0.157 \mathrm{rev} / \mathrm{mm}$ yaitu sebesar $1.097 \mu \mathrm{m}$.

Berdasarkan grafik pada gambar 6 sampai dengan gambar 9, hasil kekasaran permukaan pembubutan dari setiap spesimen benda kerja berbeda-beda setiap putaran dan laju pemakanan.

Dari hasil analisa data tersebut diatas untuk perlakuan pembubutan dry cutting nilai tertinggi kekasaran permukaan terdapat pada baja ST42 dan terkecil kekasaran permukaan terdapat pada baja ST60. Sedangkan untuk perlakuan pembubutan menggunakan metode minimum quantity lubrication (MQL) nilai tertinggi kekasaran permukaan terdapat pada baja ST42 dan terkecil kekasaran permukaan terdapat pada baja ST60. Kemudian untuk perbandingan jenis bahan benda kerja pembubutan dry cutting baja ST42 nilai kekasaran permukaannya tertinggi dan terendah terdapat pada perlakuan pembubutan menggunakan metode minimum quantity lubrication (MQL) baja ST60.

Dari semua spesimen benda kerja pembubutan dengan variasi putaran dan laju pemakanan dapat diperoleh bahwa yang memberikan kualitas kekasaran permukaan terkecil terdapat pada baja ST60 metode minimum quantity lubrication (MQL) dengan putaran $1500 \mathrm{rpm}$ dan laju pemakanan $0.157 \mathrm{rev} / \mathrm{mm}$ sebesar $1.097 \mu \mathrm{m}$.

Tampilan permukaan hasil pembubutan masing-masing spesimen benda kerja saling berbeda, yang mana terdapat bagian yang kasar dan halus pada bagian permukaannya yang dapat diamati secara visualisasi atau manual. Semua itu disebabkan adanya perbedaan putaran dan laju pemakanan yang diberikan pada setiap spesimen benda kerja pembubutan. selain itu faktor getaran pada ujung benda kerja juga menjadi penyebab adanya pengaruh pada permukaan hasil pemotongan benda kerja. Adapun tampilan-tampilan permukaan hasil pembubutan dapat dilihat pada gambar 10. 


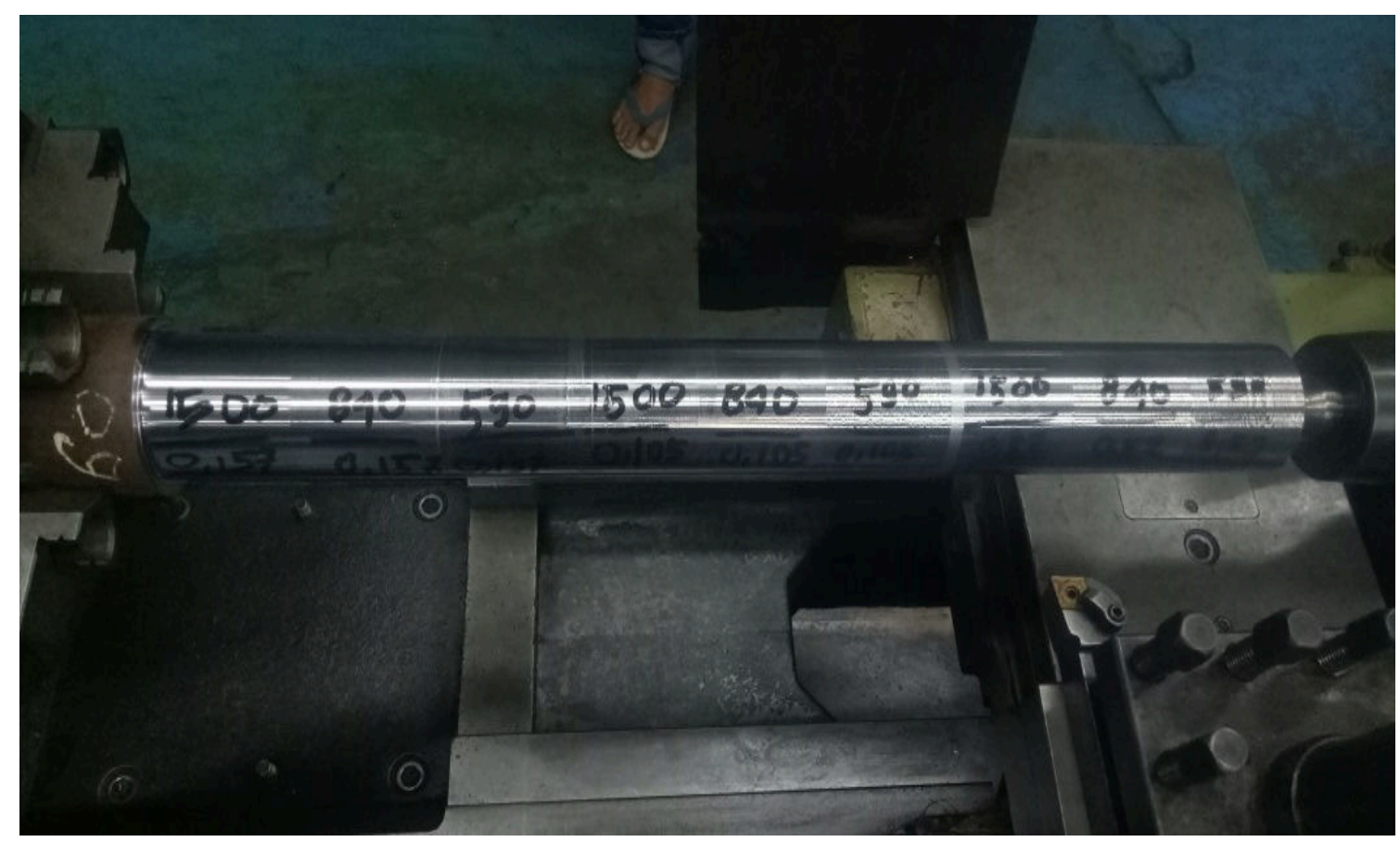

Gambar 10. Tampilan Kekasaran Permukaan hasil Pembubutan Baja ST60 MQL

\section{KESIMPULAN}

Berdasarkan hasil penelitian dan analisa data yang telah dilakukan, maka dapat disimpulkan Konsumsi daya listrik pada proses pembubutan hanya dipengaruhi oleh variabel putaran, dimana semakin besar putaran yang digunakan maka nilai konsumsi daya listrik semakin tinggi, sebaliknya semakin kecil putaran yang digunakan maka nilai konsumsi daya listrik semakin rendah. Sedangkan laju pemakanan dapat berpengaruh terhadap konsumsi daya listrik dan Media pendingin memberi pengaruh yang signifikan terhadap kekasaran permukaan benda kerja dimana jika menggunakan pendingin dengan menggunakan metode minimum quantity lubrication (MQL) (MQL) semakin besar nilai kehalusan benda kerja.

\section{DAFTAR PUSTAKA}

[1] Klocke, Fritz; Kuchle, Aaron. Manufacturing processes. Berlin: Springer, 2009.

[2] Amitabha, Ghosh; Kumar, Mallik Asok. Manufacturing science. 1999.

[3] Rochim, Taufiq. Proses Pemesinan Buku 1, 2, 3, 4. Bandung, ITB. 2007.

[4] Mardiansyah, Andri; Hendra, Hendra; Hendri, Van Hoten. Analisis kekasaran permukaan benda kerja dengan variasi jenis material dan pahat potong. 2014. PhD Thesis. Universitas Bengkulu.

[5] Kalpakjian, Serope. Manufacturing engineering and technology. Pearson Education India, 2001.

[6] Fahrulloh, Rezavani. Pengaruh Parameter Pemotongan Terhadap Kekasaran Permukaan Proses Pembubutan Konvensional. 2013. PhD Thesis. Universitas Brawijaya.

[7] Paridawati, Paridawati, et al. Pengaruh Kecepatan Dan Sudut Potong Terhadap Kekasaran Benda Kerja Pada Mesin Bubut. Jurnal Ilmiah Teknik Mesin Unisma" 45" Bekasi, 2015, 3.1: 97662.

[8] Ansyori, Anang. Pengaruh Kecepatan Potong dan Makan terhadap Umur Pahat pada Pemesinan Freis Paduan Magnesium. Mechanical, 2015, 6.1. 
51 Rusdi Nur, Edhy Gazali, Faris Farid R. Pengaruh Pembubutan Dengan Sistem Minimum Quantity Lubrication (MQL) Dan Dry Cutting Terhadap Kekasaran Permukaan Dan Konsumsi Daya Listrik Pada Baja Karbon Sedang

[9] Zubaidi, A., et al. Analisis pengaruh kecepatan putar dan kecepatan pemakanan terhadap kekasaran permukaan material FCD 40 pada mesin bubut CNC. Jurnal Ilmiah Momentum, 2012, 8.1 .

[10] Rahman, Mohamed Abd, et al. Process Capability of High Speed Micro End-Milling of Inconel 718 with Minimum Quantity Lubrication. In: IOP Conference Series: Materials Science and Engineering. IOP Publishing, 2017. p. 012036.

[11] Dhar, N. R.; Kamruzzaman, M.; Ahmed, Mahiuddin. Effect of minimum quantity lubrication (MQL) on tool wear and surface roughness in turning AISI-4340 steel. Journal of materials processing technology, 2006, 172.2: 299-304.

[12] Saini, Akash, et al. Experimental estimation and optimization of process parameters under minimum quantity lubrication and dry turning of AISI-4340 with different carbide inserts. Journal of mechanical science and Technology, 2014, 28.6: 2307-2318.

[13] Basuki, Budi. Pengaruh Metode Minimum Lubrication Keausan Pahat dan Kekasaran Permukaan Benda Kerja AISI 4340. Jurnal Teknologi, 2014, 7.2: 112-117.

[14] Gutowski, Timothy; Dahmus, Jeffrey; Thiriez, Alex. Electrical energy requirements for manufacturing processes. In: 13th CIRP international conference on life cycle engineering. Leuven, Belgium, 2006. p. 623-638. 